\title{
Aceleração ou interrupção das tendências brasileiras do subdesenvolvimento e dependência?
}

\author{
Acceleration or interruption of brazilian tendencies of \\ underdevelopment and dependence?
}

\section{¿Aceleración o interrupción de las tendencias brasileñas de subdesarrollo y dependencia?}

\begin{abstract}
Resumo: Prestes a completar duzentos anos de sua independência nacional, o Brasil encontra-se diante das preocupações com o subdesenvolvimento e a dependência externa, sobretudo com o avanço do capitalismo 4.0. Diante das intensas transformações nacionais registradas ao longo do tempo, especialmente no período mais recente, consideram-se as respostas educacional, científica e tecnologia frente ao frente ao reposicionamento brasileiro na interior da Divisão Internacional do Trabalho.
\end{abstract}

Palavras-chave: Trabalho. Educação. Tecnologia. Dependência. Subdesenvolvimento.

Abstract: About to complete two hundred years of its national independence, Brazil is facing concerns about underdevelopment and external dependence, especially with the advance of capitalism 4.0. In view of the intense national transformations recorded over time, especially in the most recent period, the educational, scientific and technological responses to the Brazilian repositioning within the International Labor Division are considered.

Keywords: Job. Education. Technology. Dependency. Underdevelopment.

Resumen: A punto de cumplir doscientos años de su independencia nacional, Brasil enfrenta preocupaciones sobre el subdesarrollo y la dependencia externa, especialmente con el avance del capitalismo 4.0. En vista de las intensas transformaciones nacionales registradas en el tiempo, especialmente en el período más reciente, se consideran las respuestas educativas, científicas y tecnológicas al reposicionamiento brasileño dentro de la División Internacional del Trabajo.

Palabras clave: Trabajo. Educación. Tecnología. Dependencia. Subdesarrollo.

\section{APRESENTAÇÃO}

Após a notável modernização capitalista experimentada entre as décadas de 1930 e 1970, o Brasil ingressou na fase atual de longo declínio. Nos últimos quarenta anos, ao registrar duas décadas perdidas do ponto de vista econômico (anos de 1980 e de 2010), a participação do país no PIB mundial decresceu de 3,2\% para menos de $2 \%$, acompanhada de considerável expansão do excedente de sua força de trabalho.

\footnotetext{
* Professor colaborador voluntário no Instituto de Economia da Universidade Estadual de Campinas. Tem experiência na área de Economia, com ênfase em Economia Social e do Trabalho, atuando principalmente nos seguintes temas: desenvolvimento, políticas públicas e relações de trabalho. E-mail: Pochmanunicampi.br.
} 
Com isso, o país alterou a sua posição relativa na Divisão Internacional do Trabalho, de país produtor e exportador de manufatura para cada vez mais dependente do comércio externo derivado do latifúndio exportador de produtos primários. Desde a forma adotada de inserção passiva e subordinada à globalização que a desindustrialização precocemente se instalou, consolidando a trajetória da estagnação da renda per capita marcada por quatro grandes recessões (1981-1983, 1990-1992, 2015-2016 e 2020).

A perda do vigor econômico que resultou no rebaixamento das condições gerais de vida da classe trabalhadora e na despedida da classe média assalariada parece aprofundar ainda mais as condições de produção do subdesenvolvimento e reprodução da dependência externa. Em consequência, o constrangimento do potencial expansionista da sociedade e da economia do conhecimento que assenta-se crescentemente no papel estratégico da educação, ciência, tecnologia e inovação.

Neste sentido que se deve considerar a relação de sintonia entre os avanços educacionais acumulados desde a Constituição Federal de 1988 e a evolução da demanda do sistema produtivo por força de trabalho qualificada e por insumos e componentes técnico-científicos. Por isso o presente ensaio constitui-se de três partes consecutivas, sendo a primeira voltada ao resgate da trajetória educacional brasileira, com ênfase no período mais recente.

A segunda parte refere-se à situação do mundo do trabalho diante do contexto econômico geral de estagnação da renda per capita das últimas quatro décadas. Por fim, a terceira parte trata da resposta educacional, científica e tecnologia brasileira ao que vem sendo denominado por capitalismo 4.0 neste primeiro quarto do século XXI.

\section{TRAJETÓRIA EDUCACIONAL}

O tardio ingresso no modo de produção capitalista sob a condição periférica na Divisão Internacional do Trabalho praticamente não terminou alterando profundamente a situação do ensino no Brasil. Ao final do século XIX, a passagem da Monarquia para a República registrou, inclusive, certo retrocesso para a educação pública, tendo em vista que a Cons- tituição de 1891 excluiu o princípio legal da garantia de livre e gratuito acesso ao ensino inscrito na Constituição do Império (1824), após a Independência nacional.

Apesar dos ideais republicanos da liberdade, igualdade, fraternidade, justiça, paz, progresso e ordem, o país seguiu convivendo com enorme atraso educacional. $\mathrm{Na}$ comparação com outras realidades nacionais, percebe-se, por exemplo, como a escolaridade média dos brasileiros permaneceu relativamente estagnada até os anos de 1930, quando passou a registrar certo impulso até chegar em 2010, com a média dos anos de estudos próxima a da Argentina, porém somente comparável a situação verificada nos EUA do início do século XX.

Além disso, a desigualdade estrutural que prevaleceu também na evolução da educação pelo interior do território nacional através do tempo. Entre o final do século XIX e o começo do século XXI, a da taxa de alfabetização dos brasileiros de cinco anos e 
mais registrou significativas diferenciação entre as cinco grandes regiões geográficas, sobretudo quando comparado o Sul com o Nordeste.

O atraso brasileiro e a sua desigualdade territorial não resultaram apenas do escasso recurso público comprometido com a educação e a ausência de convergência nacional em torno da prioridade do modelo inclusivo no ensino de qualidade. Mas, sobretudo, da reprodução continuada do descaso das elites para com as políticas nacionais e regionais de princípio emancipatório na educação.

Gráfico 01: Evolução dos anos médios de escolaridade da população com 15 anos e mais em países selecionados

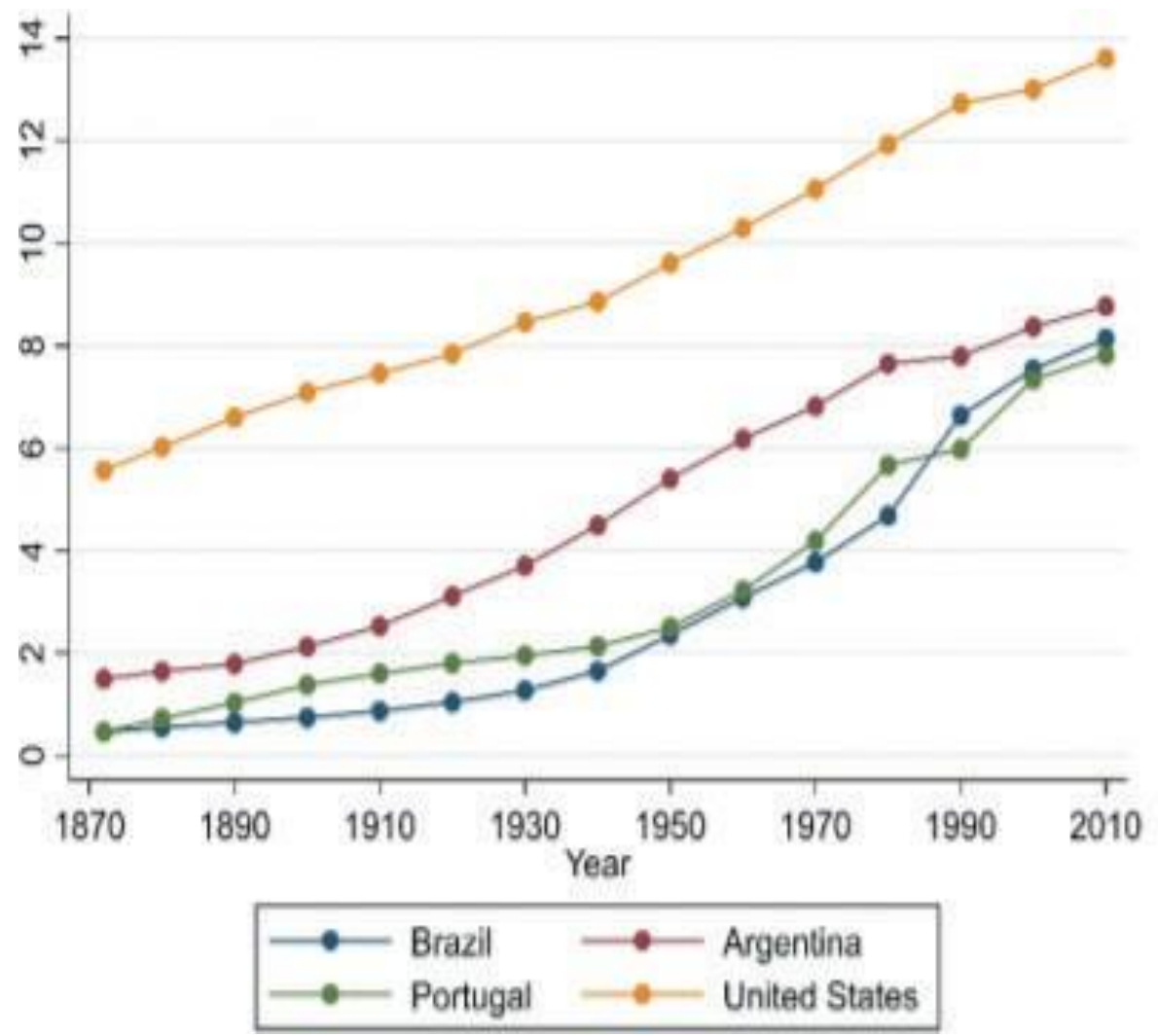

Fonte: LEEUWEN, B. et al Average Years of Education, 1850-2010. (Clio-Infra) In: KOMATSU, B. et al A História da Educação e as Origens da Desigualdade Regional no Brasil. Policy Paper, № 27, Setembro, 2017, p. 8. 
Gráfico 02: Brasil - Evolução da taxa de alfabetizados na população de 5 anos e mais em anos selecionados $(\mathrm{em} \%)$

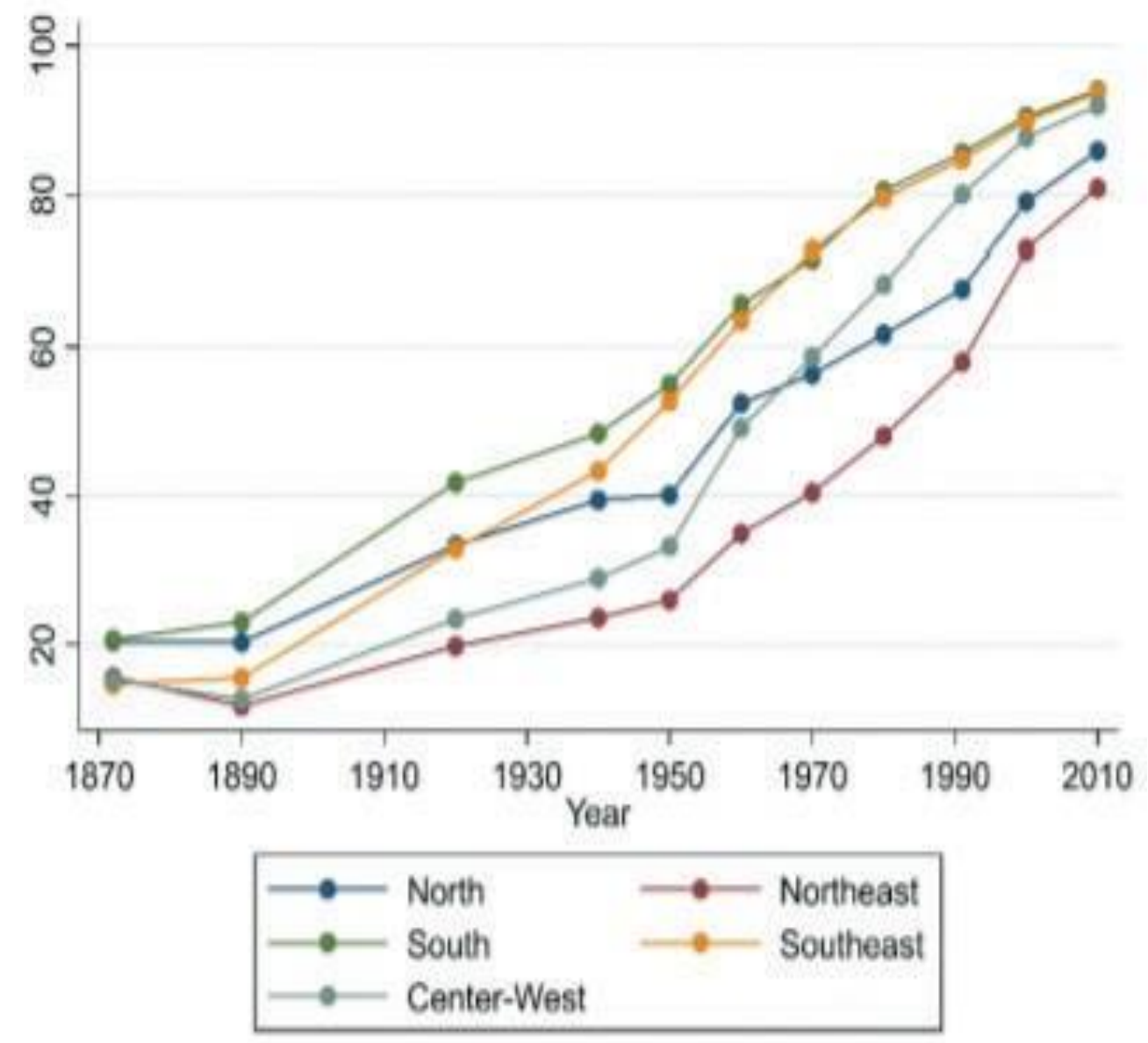

Fonte: Censos Demográficos/IBGE, In: KOMATSU, B. op cit p. 11.

Essa condição histórica decorre, em grande medida, dos antecedentes percorridos até a instalação da escola pública no Brasil. Até 1890, por exemplo, prevaleceu a descontinuidade organizacional do ensino e a própria responsabilidade estatal durante a condição de colônia portuguesa (1550-1822) e de Império (1822-1889).

Enquanto os séculos iniciais da colonização foram ocupados pela pedagogia jesuítica nas funções educacionais (1549-1759), a parte final (1759-1822) predominou o conjunto de aulas régias impulsionadas pela reforma pombalina em Portugal ${ }^{1}$. No período Imperial, a irregularidade dominou as funções educacionais, embora desde a estada provisória da família real (1808-1821) que o modelo dual de contida dimensão populacional para o ensino instaurado por faculdades e colégios estatais às elites dirigentes fosse instalado, enquanto organizava-se algumas escolas de ofícios aos trabalhadores livres.

1 Enquanto os colégios jesuítas eram financiados até a década de $1750 \mathrm{com}$ recursos decorrentes da receita tributária no período colonial, as aulas régias mantidas pela Coroa dependiam do chamado subsídio literário até a década de 1820. Com a Independência nacional, os recursos financeiros voltados à educação não atingiam a $2 \%$ do orçamento do governo imperial e 0,5\% dos orçamentos das províncias. Ver mais em: HUE, 2006 e CHAIA, 1965. 
Com a implantação da República, o conceito de escola pública alterou a longa trajetória pregressa do enfrentamento ao mal da ignorância herdado do sentido de colonização por exploração portuguesa, sem alteração relevante no Império. Para tanto, a educação assumiu tardiamente o papel resultante das mudanças entre a base material da economia e as consequências geradas na estrutura da sociedade.

O desafio de transitar do antigo e longevo agrarismo para a sociedade urbana e industrial explicitou a estratificação na formação social marcada pela presença de segmentos orgânicos vinculados à atividade econômica principal e dos inorgânicos, sobrante ao núcleo central da atividade produtiva (PRADO JR, 2011). Neste contexto estrutural da sociedade que a escola pública emergiu desafiada por seu papel validador ou não das desigualdades duráveis impostas pelo próprio desenvolvimento capitalista no país.

Tabela 01: Brasil - Evolução da composição populacional por níveis de escolaridade (em \%)

\begin{tabular}{lcccccc}
\hline Composição & $\mathbf{1 9 0 0}$ & $\mathbf{1 9 2 0}$ & $\mathbf{1 9 4 0}$ & $\mathbf{1 9 6 0}$ & $\mathbf{1 9 8 0}$ & $\mathbf{2 0 1 9}$ \\
\hline Analfabeto & 65,3 & 64,7 & 52,0 & 46 & 33 & 8 \\
\hline Fundamental & 34,1 & 34,6 & 46,8 & 51 & 54 & 44 \\
\hline Médio & 0,5 & 0,6 & 1,0 & 2 & 7 & 31 \\
\hline Superior & 0,1 & 0,1 & 0,2 & 1 & 5 & 17 \\
\hline
\end{tabular}

Fonte: IBGE (elaboração própria)

Apesar dos avanços obtidos pela consolidação do ensino, o Brasil registrou ainda no final da segunda década do século XXI, um pouco menos de $10 \%$ de sua população sem qualquer instrução. Entre 1900 e 2019, por exemplo, a proporção dos analfabetos no total dos brasileiros declinou $88 \%$ (de 65\% para $8 \%$ ), ao passo que o segmento com nível superior multiplicou a sua participação relativa por 170 vezes, o de escolaridade média por 51,7 vezes e o de ensino fundamental por 1,3 vezes.

Em treze décadas da predominância do modo de produção capitalista, a trajetória educacional esteve moldada pela escola pública com três grandes fases temporais de características distintas (SAVIANI, 2004). Nas décadas de 1890 a 1920, por exemplo, a primeira fase da escola pública marcada pela implantação e expansão dos grupos escolares voltados fundamentalmente ao meio urbano.

Trazida da Europa e dos EUA, a experiência dos grupos escolares representou a forma de organização do ensino durante a República Velha. Com turmas seriadas, as escolas graduadas surgiram a partir da reunião de estabelecimentos isolados nas cidades para a seleção e formação de elites, posto que no meio rural, onde se encontrava a maioria da população, predominava escassa presença escolar (SOUZA, 1998; VIDAL, 2006).

Por conta disso, o atraso educacional se manteve praticamente inalterado, sem 
conseguir universalizar o ensino fundamental e erradicar o analfabetismo em pleno início do século XX a custas de recursos públicos inferiores a $2 \%$ do orçamento governamental.

Ao contrário dos principais países capitalistas avançados que resolveram o deficit educacional na virada do século XX, o Brasil seguiu praticamente intocável, com cerca de 2/3 da população na condição de analfabetos entre os anos de 1900 e 1920².

Da década de 1930 a de 1950 transcorreu a segunda fase da escola pública caracterizada pela estruturação inicial do sistema educacional em dimensão nacional. Para tanto, a criação do Ministério da Educação e da Saúde Pública em 1930 conferiu ao Estado crescente responsabilidade pela política de enfrentamento às múltiplas dimensões do atraso no ensino brasileiro.

Para a educação, o projeto político de formação de construção nacional procurou responder aos problemas socioeconômicos decorrentes da passagem para a sociedade urbana e industrial, com demandas crescentes tanto da escola laica e pública no ensino fundamental e médio gratuito como da nova pedagogia assumida pelo monopólio estatal. Nesse sentido, a base do financiamento da educação pública se mostrou essencial, passando de $1,9 \%$ do orçamento do governo federal, de $15 \%$ das províncias e de $8,1 \%$ dos municípios na década de 1930 para 5,7\% das despesas da União, 13,7\% dos estados e $11,4 \%$ dos municípios nos anos de $1950^{3}$.

Gráfico 3: Brasil - Evolução da taxa média anual de variação da população e do total das matrículas por nível de ensino em anos selecionados (em \%)

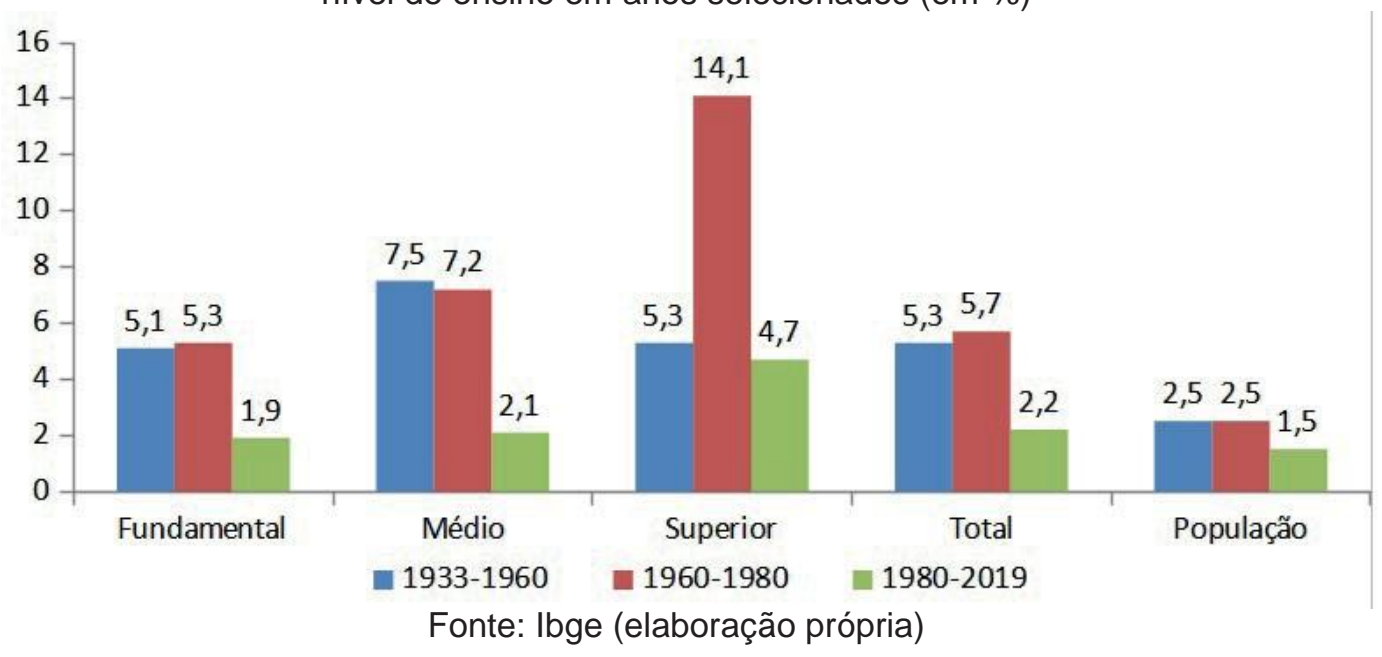

A implantação do sistema nacional de educação acompanhada pela ampliação dos recursos públicos permitiu expandir o total das matrículas ao ritmo médio anual de 5,7\% entre os anos de 1933 e 1960. No que se refere aos diferentes níveis de ensino, o Médio

2 O número absoluto de iletrados passou de 6,3 milhões de residentes em 1900 para 11,4 milhões em 1920 Por se encontrar concentrado fundamentalmente na base da pirâmide social, o analfabetismo encontrava-se distante da agenda as elites políticas agraristas, expressando certa visão eugenista durante e República Ve- Iha. Sobre isso ver: GUIRALDELLI JR, 1990; DÁVILA, 2003; RAMOS, 1939; PINTO, 1960.

3 Entre as décadas de 1930 e 1950, o gasto médio anual da educação total em relação ao orçamento pú- blico agregado da União, estados e municípios saltaram de 6,2\% para 10,3\%. Ver mais em RIBEIRO, 2003; KANG, 2011. 
foi o que cresceu mais rapidamente $(7,5 \%)$, seguido do Superior $(5,3 \%)$ e do Fundamental $(5,1 \%)$ durante o idêntico período de tempo.

Mesmo assim, o país detinha ainda em $1960,46 \%$ de sua população considerada analfabeta (11,5\% a menos do que em 1940). Ainda no ano de 1960, a distribuição dos brasileiros por nível de ensino era de 51\% com Ensino Fundamental (8,5\% superior ao do ano de 1940), de 3\% com Ensino Médio (100\% maior que em 1940) e de 1\% com Ensino Superior (10 vezes maior que em 1940).

Esses avanços, ainda que contidos para a dimensão do atraso educacional no país, apontaram novos espaços para a reformulação do ensino, capazes de constituir a terceira fase da escola pública que alcança dos dias de hoje no Brasil. Por característica principal, o período posterior a década de 1950 tem sido marcado pela presença de diretrizes nacionais para o desenvolvimento da educação, com recursos previamente definidos em legislação própria para o financiamento, metas e avaliações sistemáticas ${ }^{4}$.

Diferentemente do complexo da saúde que conseguiu constituir um sistema único de dimensão nacional, a educação estabeleceu um sistema complexificado por diferenças de responsabilidades nas três esferas da federação (União, estados e municípios). Sem unidade sistêmica, a diversidade educacional nos estados e municípios prevaleceu fecunda pelo brutal diferencial de realidades próprias do subdesenvolvimento e da dependência externa que assenta a nação desde a sua origem.

Não obstante o avanço do acesso à educação, com a universalização alcançada no ensino fundamental, assistiu-se muito mais a manifestação da massificação do ensino que propriamente a democratização educacional aos brasileiros em pleno início da terceira década do século XXI. Para além dos importantes aspectos educacionais quantitativos, ganharam cada vez mais importância as especificidades que se vinculam à qualidade no ensino e aprendizagem ${ }^{5}$.

Isso parece ter importância ainda maior com a difusão no uso de métodos educacionais instados pelas novas tecnologias de informação e comunicação no ensino a distância, gamificação, entre outras formas de simplificação da capacitação de usuários como viedograme com algum conteúdo informativo. Para, além disso, a transferência da soberania da produção e difusão do conhecimento das escolas e universidades integradas às grandes corporações transnacionais privadas (gerência do correio eletrônica, armazenamento de dados, plataformas de trabalho e redes sociais) e a uberização do trabalho docente e de pesquisa próprio do capitalismo acadêmico a rebaixar o papel da educação no processo civilizatório.

\footnotetext{
1 No ano de 1965, por exemplo, os recursos públicos para a educação e cultura era e 9,6\% do orçamento da União, enquanto a partir da Constituição de 1988 passou a ser de $18 \%$ na União e de $25 \%$ para estados e municípios. Apesar disso, os recursos educacionais foram sequestrados por medidas de contenção orçamentárias, como a introdução desde os anos de 1990 da Desvinculação das Receitas da União que retira 20\% das vinculações orçamentárias do governo federal. Mais detalhes em: MELCHIOR, 1981. ROCHA ; GIUBERTI, 2007.
}

2 Sobre o debate em torno da qualidade da educação ver: BUARQUE, 2011; FAMOS ; ROITMAN, 2011; GAUMÃO, 2010; OLIVEIRA, 2012; OLIVEIRA, 2012; GENTILI ; SILVA, 1995; GADOTTI, 2013. 


\section{SENTIDO ECONÔMICO E PERFIL OCUPACIONAL}

Em plena virada para o século XXI, as modificações no sistema capitalista global trouxeram novos desafios à superação do atraso brasileiro. $O$ enfrentamento do subdesenvolvimento e da dependência externa herdada da condição periférica imposta pela inserção tardia no modo de produção capitalista somente ganhou evidência com a Revolução de 1930, quatro décadas após o liberalismo conduzir a ordem social competitiva numa economia atrasada por longo passado colonial e escravista.

Por meio século, o país registrou notável trajetória econômica, identificada como uma das economias nacionais mais dinâmicas do mundo a transitar do antigo e longevo agrarismo para uma nova sociedade urbana e industrial. Com a internalização do sistema de produção manufatureira e a estruturação da sociedade de massas com mobilidade social e modernização do padrão de consumo, o Brasil deixou de equivaler a $1 \%$ da economia mundial, em 1930, para atingir a 3,2\%, em 1980.

Essa fase áurea do desenvolvimento nacional esteve associada a pelo menos dois aspectos externos essenciais. O primeiro vinculado à substituição do imperialismo de hegemonia inglesa vigente até a primeira Guerra Mundial (1914-1918) pelo Sistema Interestatal consolidado a partir do fim da segunda Guerra Mundial (1939-1945) e da vigência da Guerra Fria (1947-1991).

O segundo aspecto externo decorreu da estabilidade tecnológica herdada da segunda Revolução Industrial do final do século XIX. Em função disso, o padrão de produção e distribuição dominante do segundo após guerra mundial de tipo american of life foi introduzido e generalizado nos estratos médio e superior com o crescimento da renda e a diversificação da demanda estimulada pela presença das empresas multinacionais, sobretudo estadunidense e europeia no Brasil.

Assim, o processo intenso de modernização nacional concedeu traços específicos a caracterizar um país periférico que converteu a sua população composta de cerca de $80 \%$ habitantes no meio rural em quase $90 \%$ de residentes urbanos ao longo do século XX. Diante da realização recorrente postergada internamente das reformas clássicas do capitalismo contemporâneo como, por exemplo, a fundiária, tributária e social, os fundamentos do subdesenvolvimento e da dependência externa se mantiveram ativos, explicitados por significativa e ampla heterogeneidade estrutural e conservadorismo constitutivo das elites dirigentes.

Desde a década de 1980, contudo, o Brasil tem sofrido significativa inflexão em sua trajetória pregressa de modernização capitalista. Contribui para isso, a forma neoliberal com que o país ingressou e perseguiu no processo de globalização, responsável pela considerável modificação no funcionamento do sistema interestatal vigente desde a segunda Guerra Mundial.

Nestes últimos 40 anos, por exemplo, as grandes corporações transnacionais se estabeleceram mais grandiosas que muitos países, sofisticando ainda mais a estrutura oligopolizada de competição intercapitalista no sistema de produção e distribuição de 
dimensão global. Com isso, a Divisão Internacional do Trabalho derivada dos arranjos econômico-financeiros do acordo de Bretton Woods e do beneplácito político-militar da Guerra Fria passou a emitir sinais de alterações provenientes do reposicionamento dinâmico dos Estados nacionais.

A dissolução da União Soviética em meio ao enfraquecimento relativo da Alemanha e Japão nos anos de 1990 concedeu aos Estados Unidos inédita posição de supremacia econômica, monetária e militar no cenário mundial. A emergência chinesa, todavia, parece conferir mais recentemente à Eurásia, a possibilidade de conformar um novo centro dinâmico no interior do sistema global, ainda que fortemente questionado e cada vez mais polarizado pelos EUA.

Neste início da terceira década do século XXI, a problemática do desenvolvimento na periferia capitalista encontra-se ainda mais desafiada pelas transformações impostas na marcha e contramarcha da globalização. Também o receituário neoliberal em curso desde o Consenso de Washington, há mais de trinta anos, sofre importante desgaste, seja pela crise de dimensão global ocorrida em 2008, seja pela pandemia da Covid-19 em 2020.

Além disso, a deterioração nos regimes democráticos têm sido registrada por suas instituições de representação de interesses, cada vez mais corroídas. Os sintomas disso parecem decorrer da crescente subordinação da política à lógica dos mercados, especialmente o de natureza financeira.

O caso brasileiro, após ter experimentado o exitoso ciclo de expansão produtiva e ocupacional entre as décadas de 1930 e 1970, revela trajetória declinante na economia e desestabilizadora do trabalho, expressa pela explosão dos supranumerários nas últimas quatro décadas. Em grande medida, o tranco no processo de acumulação de capital derrubou a taxa de lucro e provocou o movimento de acomodação dos capitalistas acompanhado do sentido neocolonial de metamorfose da burguesia industrial em negociantes do rentismo, em montadores/comerciantes de componentes industriais, em expropriadores de recursos naturais e de promotores de atividades serviçais.

A reprimarização na pauta de exportação e a desindustrialização precoce concederam à terciarização econômica anêmica em termos do expansionismo do conjunto das atividades produtivas, retrocedendo a representação de menos de $2 \%$ do PIB mundial. Do mesmo modo, a submissão dos governos à emergência do presentismo imposto pela rigidez do receituário neoliberal terminou por estancar o sentido de queda na taxa de lucro desde a década de 1990 com a inserção passiva e subordinada à globalização.

De lá para cá, a economia brasileira entrou em rota de regressiva, dependendo cada vez mais das decisões tomadas no exterior, ainda que isso não tenha ocorrido mediante reações em diferentes momentos pontuais de tentativas frustradas de retomar o horizonte desenvolvimentista. A trajetória do apequenamento brasileiro tem sido revelada por duas décadas perdidas (1980 e 2010) somente nos últimos quarenta anos.

Logo no final dos anos de 1970, as decisões econômicas dos EUA produziram a crise da dívida externa que tornou a década brasileira perdida. Nos anos de 1990, a forma 
submissa de inserção na globalização terminou por comprometer qualquer possibilidade de integração soberana às cadeias globais de valor.

Apesar da retomada de certo protagonismo socioeconômico nos anos 2000 , inclusive com certo sucesso no enfrentamento da crise financeira de dimensão global de 2007-2009, a segunda década do século XXI foi perdida, sobretudo com a recessão de 2015-2016 e o retorno ao receituário neoliberal. A perda de vitalidade do capitalismo brasileiro revela longa fase do declínio econômico prevalecente nos últimos quarenta anos de retrocesso na industrialização acompanhada pela precocidade da terciarização produtiva e ocupacional.

Entre os anos de 1981 e 2019, por exemplo, a economia brasileira moveu-se ao ritmo de apenas $2 \%$ com média anual, registrando o sentido da estagnação na renda per capita. No período anterior de 1945 a 1980, o capitalismo em expansão percorreu a trajetória do crescimento médio anual de 7,3\% (Pib per capita de crescimento médio 4,5\% ao ano).

Na comparação entre os dois períodos de tempo, o declínio econômico fica evidente. Nos últimos quarenta anos, a vitalidade econômica equivaleu a somente $27 \%$ do que ocorreu com a expansão da renda nacional de 1945 a 1980.

Nesse sentido que se percebe como a economia brasileira terminou alterando drasticamente o seu comportamento desde o último quinto do século XX. Em grande medida refletiu a queda na taxa de lucro como esgotamento do ciclo da industrialização nacional no ingresso dos anos de 1980.

A adoção do receituário neoliberal desde 1990 se mostrou suficiente para estancar a continuidade da queda na taxa de lucro, porém insuficiente para retomar o patamar vigente anteriormente. Por conta disso, o país passou a conviver com crescente desestabilização do trabalho e elevada formação de excedentes da força de trabalho às necessidades do capital produtivo, cada vez mais submetido à lógica da dominância financeira.

A longa estagnação da economia brasileira tem sido acompanhada pela maior disponibilidade do trabalho às necessidades de valorização do capital, favorecendo o aparecimento de novas formas de gestão dos supranumerários. Durante o ciclo da industrialização nacional vigente entre as décadas de 1930 e 1970, a problemática da integração da massa de inorgânicos herdada da sociedade agrária foi enfrentada por duas vias.

A primeira relacionada ao projeto de sociedade salarial aberto a partir do trabalho escravo posto na ilegalidade, em 1888. A motivação da inclusão social pelo emprego assalariado sofreu inédita ampliação com a perspectiva da cidadania regulada por direitos sociais e trabalhistas desde a década de 1920, com a aprovação da primeira lei da previdência social (Lei Eloy Chaves, em 1923).

Com a Consolidação das Leis do Trabalho, 20 anos depois, os direitos sociais e trabalhistas começaram a avançar para o empregado assalariado urbano e formal com o simbolismo da carteira de trabalho. Duas décadas depois, a ocupação rural também passou a ser lenta e gradualmente incluída no sentido da cidadania regulada com a aprovação do Estatuto do Trabalhador Rural, em 1963.

Apesar do dinamismo econômico e do avanço dos direitos sociais e trabalhistas 
durante o ciclo da industrialização nacional e da cidadania regulada, o Brasil detinha na década de 1980 somente a metade de sua a força de trabalho incluída no emprego assalariado formal. Considerada informal, a parte restante da força de trabalho encontrava-se semiconectada ao processo de exploração capitalista, sem a percepção de estar necessariamente excluída, pois funcional à lógica da produção e consumo na sociedade urbana e industrial. Nesse sentido, a segunda via de integração transcorreu pela própria dinâmica da reprodução do subdesenvolvimento brasileiro. A acelerada expansão econômica se mostrou significativa para expansão de empregos assalariados que cobriam cerca de 2/3 dos ocupados na década de 1980.

Mesmo assim, 1/3 das ocupações seguia ainda não assalariada (autônomos, conta própria, trabalhador independente, empregador e outros), enquanto $1 / 4$ do total dos assalariados não tinham emprego formal. A gestão da metade da força de trabalho sem acesso aos direitos sociais e trabalhistas decorrentes do emprego assalariado formal encontrava-se amparada tanto na mobilidade social ascendente dos migrantes aos grandes centros urbanos como na modernização ampliada do padrão de consumo capitalista.

Gráfico 04: Brasil - evolução das taxas de atividade, de assalariamento, assalariamento formal e inatividade remunerada (em \%)

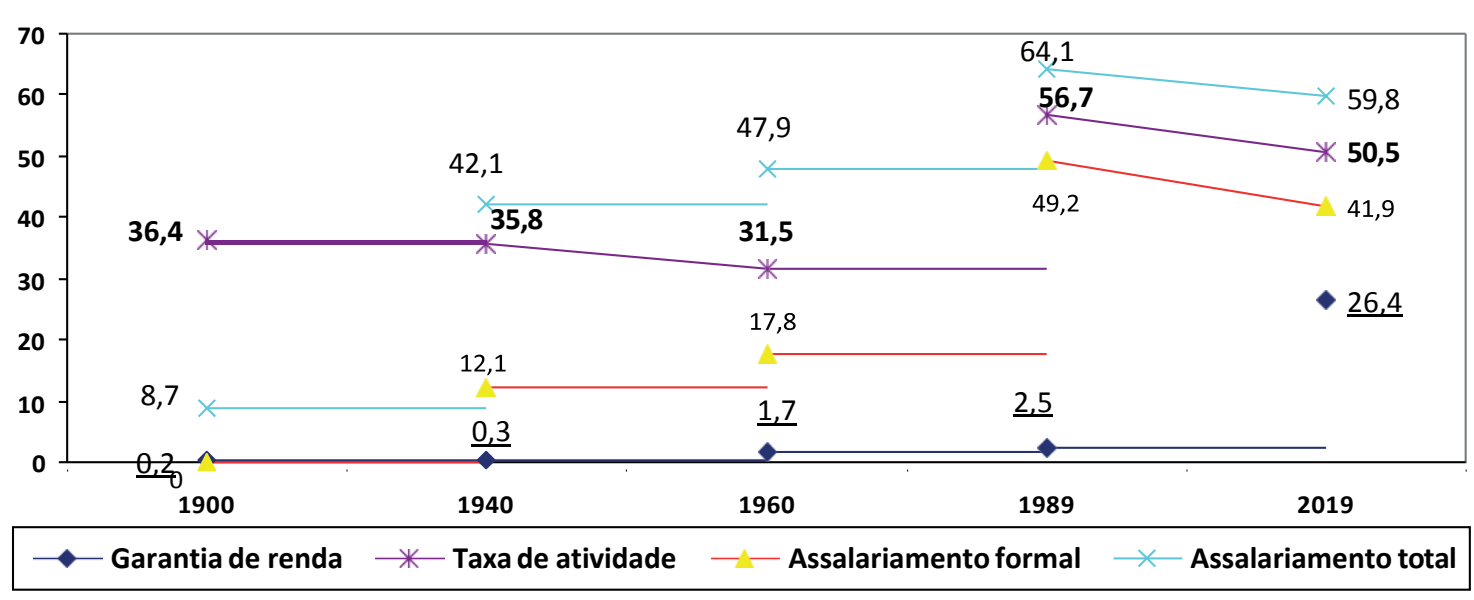

Fonte: Ibge, ME (elaboração própria) Garantia de renda equivale ao número de beneficiários de transferência de renda do fundo público com aposentadoria e pensão, bolsa famílias, seguro-desemprego, seguro social rural e benefício de prestação continuada em relação oa todal da população; taxa de atividade também refere-se à relação da População Economicamente Ativa (PEA) com a População em Idade Ativa (PIA), assalariamento total resulta da relação entre o total de empregados assalariados e a PEA, e o assalariamento formal resulta da relação entre emprego assalariado formal (com carteira assinada $e$ emprego público) e a PEA.

A continuidade da trajetória de queda na taxa do lucro ao longo da década de 1980 apontou para o esgotamento do projeto nacional desenvolvimentista. De um lado pela asfixia da industrialização volta ao mercado interno decorreu das consequências do ajuste estadunidense e, de outro, pela própria desindustrialização promovida pelo ingresso passivo e subordinado na globalização desde os anos de 1990.

Neste contexto de importantes mudanças na estrutura produtiva, a integração ativa 
da força de trabalho pela vitalidade do crescimento econômico sofreu significativo abalo. O estancamento na queda da taxa de lucro somente foi reestabelecido com a implantação do receituário neoliberal durante a "era dos Fernandos" (Collor, 1990-92 e Cardoso, 19952002), sobretudo no atendimento dos interesses do patronato pela redução de custos e rigidezes laborais, bem como na ampliação da privatização e financeirização do Estado e suas políticas sociais.

Diante do salto na geração de supranumerários, cada vez mais excedente à necessidade da acumulação capitalista com a imposição da estagnação da renda per capita, o trabalho foi sendo cada vez mais desestabilizando. Na realidade, a conformação do neo-pauperismo enquanto nova questão social do início do século XXI.

Por um lado, a superpopulação relativa a se reproduzir nas formas de geração de trabalho e renda associada ao fenômeno do trabalho informal precarizado e flexível. Por outro, a composição da classe trabalhadora de serviços por parcelas crescentemente sem identidade ao lumpesinato tradicional, excluído, pois muito menos exposto à condição de reserva a ser possivelmente convocado por um sistema produtivo incapaz de não mais absorvê-lo.

Após meio século de construção da sociedade salarial na perspectiva da cidadania regulada, o sentido da estruturação do mercado de trabalho, ainda que incompleto, passou a ruir, com retrocessos inegáveis. Entre 1989 e 2019, por exemplo, a taxa de assalariamento apresentou inédita redução de 6,7\%, passando de 64,1\% da PEA para $59,8 \%$, enquanto o emprego formal diminuiu em $14,8 \%$ (de $49,2 \%$ da PEA para $41,9 \%$ ).

Com isso, o universo de ocupados não assalariados saltou de 35,9\% da PEA, em 1989, para 40,2\%, em 2019, registrando a elevação de $12 \%$ no período. Ao mesmo tempo, a participação dos empregados informais na PEA aumentou de 23,2\%, em 1989, para $29,9 \%$ e a do desemprego aberto cresceu de $3 \%$ para $11 \%$, sem incluir os desalentados e subutilizados da População Economicamente Ativa.

Com o receituário neoliberal, a flexploração do trabalho ganhou significado na gestão da força de trabalho através da difusão do regime da insegurança do emprego pela terceirização e precarização do trabalho multifuncional. Durante a estagnação da renda per capita, os postos de trabalho abertos concentraram-se na base da pirâmide social, uma vez que o estoque trabalhador com rendimento de até dois salários-mínimos reais saltou de 68,1\% dos ocupados para 70,7\% entre 1986 e 2016.

Para o mesmo período de tempo, os ocupados com rendimento acima de 5 salários mínimos decresceu de 9,9\% para 8\%. Assim, os postos de trabalho com maior remune ração decresceram $19,2 \%$ a sua participação relativa no total dos ocupados entre os anos de 1986 e 2016, enquanto o emprego de força de trabalho com remuneração de até dois salários-mínimos aumentou em 3,8\% no mesmo período de tempo.

$\mathrm{O}$ apequenamento das classes médias assalariadas e dos trabalhadores industriais resultou do esvaziamento na indústria e na estagnação na produtividade do trabalho. Sem o crescimento econômico sustentável e a substituição da base manufatureira pelo agressivo inchamento do setor de serviços, a produtividade somente poderia estancar, mesmo com importantes esforços nas pesquisas em ciência, tecnologia e inovação, no ensino superior 
(ampliação da graduação, mestrados e doutorados) e na produção acadêmica indexada que seguiu nem sempre conectada às necessidades do desenvolvimento nacional, ao mercado de trabalho e à geração e internalização de patentes para o setor produtivo ${ }^{6}$.

\section{DEPENDÊNCIA TECNOLÓGICA S SUBDESENVOLVIMENTO NO CAPITALISMO}

4.0

Neste início da terceira década do século XXI, a complexidade do capitalismo 4.0 expõe um conjunto de desafios à humanidade e, em especial, ao desenvolvimento brasileiro. Essas grandes mudanças convergentes com o salto tecnológico digital, físico e biológico tem impactado o Sistema Interestatal vigente desde o final da Segunda Guerra Mundial? ${ }^{7}$.

No rastro das transformações que se acumulam, outra estrutura socioeconômica se conforma sob o impacto direto e desigual entre indivíduos e coletividades submetidas ao sistema informacional a questionar a própria forma de ensino e de produção e difusão da ciência, tecnologia e inovação ${ }^{8}$. Neste sentido, o risco crescente de aprofundamento do subdesenvolvimento a reproduzir a decadência tecnológica externa.

No caso brasileiro, as bases do Sistema Nacional de Ciência, Tecnologia e Inovação (SNCTI) remontam ao início da década de 1950, quando o segundo governo Vargas (19511954) implantou o Conselho Nacional de Desenvolvimento Científico e Tecnológico (CNPq) e a Coordenação de Aperfeiçoamento de Pessoal de Ensino Superior (CAPES). Uma década depois, com a ditadura civil-militar (1964-1985), a educação superior sofreu considerável transformação com a implementação e expansão do modelo de universidade assentado na teoria do capital humano e na especialização do conhecimento aprofundada pela própria montagem do ensino de pós-graduação9.

Com a redemocratização política do país, o Sistema Nacional de Ciência, Tecnologia e Inovação e o ensino brasileiro, sobretudo o superior, foram expostos a modificações significativas decorrentes, em grande medida, do receituário neoliberal. Pelo ingresso passivo e subordinado na globalização desde 1990, o ensino superior, por exemplo, terminou aprofundando o modelo da universidade-empresa, enquanto o SNCTI se reorganizou influenciado pelo inovacionismo ${ }^{10}$.

Desde então, o capitalismo acadêmico passou a ganhar cada vez mais importância as políticas educacionais e científicas amparadas no rastro do inovacionismo e produtivismo contaminado pela mercantilização da educação e fortalecimento da concepção do direito de propriedade intelectual ${ }^{11}$. O avanço no processo de empresariamento da produção do conhecimento técnico-científico e do regime de trabalho de professores e pesquisadores coincidiu com o aprofundamento do sentido da dependência tecnológica externa, o contribuiu para 0 aprofundando do subdesenvolvimento brasileiro.

6 Para mais detalhes, ver: MATTOS, 2011; GOMES, 2011; SALM, 1991, SANTOS, 1979, DRAIBE, 1985; FERREIRA, 2020; POCHMANN, 2004.

7 Ver, por exemplo, DOWBOR, 2020; UNCTAD, 2019; BARÓN, 2004, PAULANI, 2012. 
Tabela 02: Brasil - indicadores de evolução do ensino, ciência e tecnologia

\begin{tabular}{|l|c|c|c|}
\hline \multicolumn{1}{|c|}{ Ítens } & $\mathbf{1 9 8 7}$ & $\mathbf{2 0 0 0}$ & $\mathbf{2 0 1 8}$ \\
\hline Universitários formados & $224,8 \mathrm{mil}$ & $359,8 \mathrm{mil}$ & $912,4 \mathrm{mil}$ \\
\hline Mestres formados & $4,7 \mathrm{mil}$ & $19,3 \mathrm{mil}$ & $50,9 \mathrm{mil}$ \\
\hline Doutores formados & $1,2 \mathrm{mil}$ & $5,7 \mathrm{mil}$ & $22,9 \mathrm{mil}$ \\
\hline Total de formandos & $230,7 \mathrm{mil}$ & $384,8 \mathrm{mil}$ & $986,2 \mathrm{mil}$ \\
\hline Artigos indexados (1) & $0,4 \%$ & $1,1 \%$ & $2,5 \%$ \\
\hline Patentes (2) & - & $0,1 \%$ & $0,1 \%$ \\
\hline Taxa de inovação nas empresas (3) & - & $31,5 \%$ & $33,6 \%$ \\
\hline Taxa de inovação real nas empresas (4) & - & $10,3 \%$ & $3,9 \%$ \\
\hline Pagamento de royalties (5) & 0,2 bi US\$ & 0,9 bi US\$ & 2,1 bi US \\
\hline Saldo comercial de alta tecnologia(6) & 2,6 bi US\$ & $-6,4$ bi US\$ & $-19,4$ bi US\$ \\
\hline
\end{tabular}

Fonte: Ibge, Bace, Mec, Scopus, USPTO (1) Porcentagem de artigos do Brasil em periódicos indexados pela Scopus em relação ao total mundial; (2) Porcentagem de patentes obtidas pelo Brasil junto a USPTO em relação ao total mundial; (3) Porcentagem das empresas que realizaram pelo menos uma inovação, conforme Pintec/lbge em 2000 e 2017; (4) Porcentagem das empresas que realizaram atividades internas de Pesquisa e Desenvolvimento, conforme Pintec/lbge em 2000 e 2017; (5) Valor transferido na conta do balanço de pagamento do país como royalties e serviços de assistência técnica, segundo Bacen; (6) Saldo na balança comercial entre exportação e importação de bens e serviços de alta intensidade tecnológica, segundo Bacen.

Enquanto o total de formandos no ensino superior e de pós-graduação foi multiplicado por 4,3 vezes entre os anos de 1987 e 2018, a taxa de inovação real nas empresas, por exemplo, regrediu consideravelmente (62\% entre os anos de 2000 e 2018) e as patentesbrasileiras permaneceram relativamente estabilizadas, praticamente insignificantes na contabilidade mundial. Com a multiplicação por 19,1 vezes no total de doutores formados e por 10,8 vezes na quantidade de mestres formados, o Brasil elevou a sua presença relativa do registro de artigos técnico-científicos no mundo, multiplicada que foi por 6,2 vezes entre 1987 e $2018^{12}$.

O importante processo de elevação do registro de artigos técnico-científicos no mundo transcorreu desassociado da maior integração dos avanços educacional e científico no interior do sistema produtivo. As empresas, por exemplo, perderam capacidade inovativa, permanecendo em patamar muito contido no padrão competitivo internacional.

A busca pelo produtivismo, como parte fundante do modelo universidade-empresa constituído no Brasil, terminou por não aproximar o mundo da produção acadêmica das necessidades do sistema produtivo nacional. No sentido do capitalismo acadêmico, o capital humano cresceu com a significativa expansão dos formados no ensino universitário e pós-graduação.

8 Mais detalhes, encontram-se em: ZUBOFF, 2019; BRUNO et al, 2018; MOROZOV, 2018; SOUZA et al 2019.

9 Para mais detalhes ver: PELAEZ; SZMRECSÁNYI, 2006; FERNANDES, 1975; RIBEIRO, 1975; TEIXEI- RA, 1969.

10 Sobre isso, ver: BANCO MUNDIAL, 1995; CARLOTTO, 2013; OLIVEIRA, 2013; OURIQUES; RAMPI- NELLI, 2017.

11 Sobre o capitalismo acadêmico, ver: COSTA ; GOULART, 2018; BORGES, 2009; MAUÉS, 2008; SLAU- GHTER ; RHOADES, 2004. 
Assim, o aumento na qualificação da mão de obra, com pesquisadores cada vez mais qualificados, conviveu com dois tipos de situação em parte reveladora do excedente de força de trabalho aos requisitos da baixa acumulação de capital. Com a estagnação da renda per capita nas últimas quatro décadas, o emprego de pesquisadores, por exemplo, concentrou-se nas instituições de ensino, com diminuição relativa no setor privado.

Gráfico 05: Brasil - Evolução da composição do conjunto de mestres e doutores empregados por natureza jurídica empregatícia em anos selecionados (em \%)

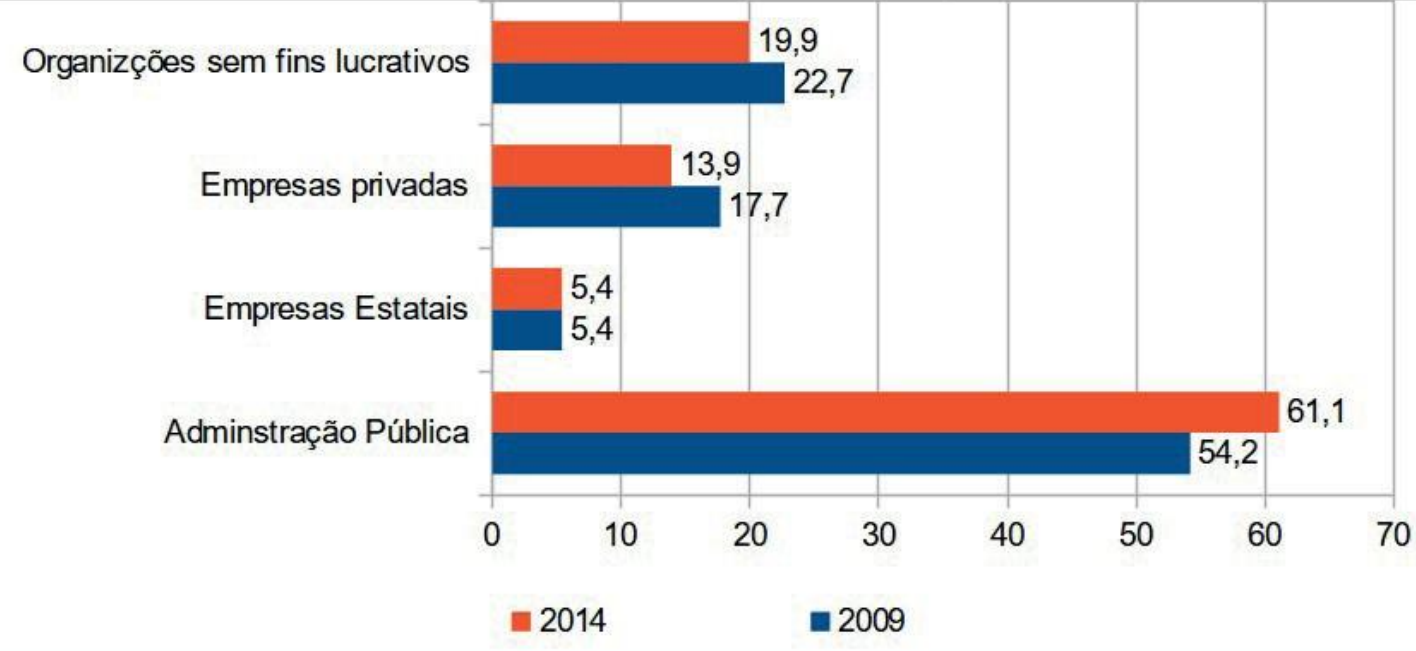

Fonte: CGEE Mestres e doutores 2015 Estudos da demografia da base técnico-científica brasileira. Brasília: CGGE, 2016.

No ano de 2014, por exemplo, a população conformada de doutores e mestres foi estimada em de 613,7 mil em todo o país. Deste universo, 68,5\% estava empregada formalmente, sem haver registro sobre a situação ocupacional ou não da parte restante de quase $1 / 3$ de doutores e mestres.

Do conjunto de mestres e doutores ocupados em empregados assalariados formais, quase $2 / 3$ pertenciam à administração pública (federal, estadual e municipal. Se considerar ainda o contingente de empregados nas empresas estatais $(5,4 \%)$, o Estado brasileiro concentrou $66,5 \%$ de toda a população com doutorado e mestrado no Brasil.

De outra parte, o desinteresse crescente do setor privado pela contratação de trabalhadores com maior escolaridade sobretudo os detentores de certificados de doutorado em mestrado no Brasil. Na comparação da população com doutorado e mestrado empregada, o setor privado reduziu em $21,5 \%$ a sua participação relativa no emprego assalariado for- mal de 17,7\% do total em 2009 para 13,9\% em 2020.

12 A evolução do Brasil na quantidade de matrículas no ensino superior avanços significativamente durante a ditadura militar, pois passou de apenas $0,7 \%$ do total os alunos de agraduação no mundo, para 2,7\%, em 1980. Com a redemocratização, o Brasil continuou a aumentar a sua presença no total das matrículas do ensino superior, atingindo a 3,3\% em 2018. Mais detalhes em: UNESCO, 2019. MEYER; SCHOFER, 2005; KRÜCKEN et al, 2007. 
A administração pública, por sua vez, aumentou o emprego de doutores e mestres em 12,7\% entre os anos de 2009 e 2014. As organizações sem fins lucrativos também diminuiram o peso relativo no emprego de doutores e mestres em $12,3 \%$, enquanto as empresas estatais permaneceram estáveis no mesmo período de tempo ${ }^{13}$.

Sem a sintonia entre a trajetória do setor produtivo e a do complexo educacional e SNCTI, o país passou a manter-se dependente do acesso à tecnologia externa. Exemplo disso foi o aumento no pagamento crescente de royalties e serviços de assistência técnica, cujo valor passou de cerca de duzentos milhões de dólares, em 1987, para mais de dois bilhões, em 2018.

No sentido da dependência tecnológica do exterior, a inserção brasileira na Divisão Internacional do Trabalho terminou sendo reposicionada. De anteriormente produtor e exportador de bens industriais com crescente valor agregado, o Brasil assumiu cada vez mais a "vocação" agropecuária e extrativa, dependendo das exportações de commodities, inclusive com sérias implicações para o meio ambiente.

Entre as décadas de 1920 e 1980, por exemplo, a participação da população rural no total dos brasileiros saltou de mais de $80 \%$ para menos de $1 / 3$. Simultaneamente, a presença dos produtos primários no total das exportações do país decaiu de próximo de $100 \%$ para menos de $1 / 3$.

Por outro lado, a população rural na década de 2010 aproximou-se de 10\% do total dos brasileiros, enquanto os produtos primários ultrapassaram a 2/3 do total das exportações. Ao mesmo tempo, o país que respondia por 3 bens industriais a cada 100 produtos manufaturados em 1980 regrediu para apenas 1 em 100 no ano de 2019.

Ademais das transformações estruturais pelas quais passam o Brasil, o capitalismo 4.0 recoloca questões essenciais para o complexo educacional e o SNCTI. A perspectiva neoliberal de implantação do capitalismo acadêmico, constituiu a imagem de mercado com compradores e ofertantes de ensino e produção técnico-científica, cuja mercantilização do da produção e difusão do conhecimento seria essencial para países considerados em desenvolvimento.

O produtivismo e o inovacionismo que contaminam atualmente o Brasil seguem sem responder adequada e satisfatoriamente os desafios impostos ao desenvolvimento na periferia do capitalismo mundial. Por conta disso que as tendências do subdesenvolvimento e da dependência externa parecem ter sido aceleradas, ao invés da necessária interrupção.

13 Ainda que o foco da análise seja o movimento geral, não se pode deixar de mencionar experiências de combinação exitosa do ensino, a ciência e a tecnologia com a inovação em empresas privadas e sobretudo, estatais como, por exemplo, a Embrapa, Embraer/Finep, Eletrobrás e Petrobras. Também as situações de universidades com produção do conhecimento associado às demandas do desenvolvimento nacional. Embo- ra sejam quase exceções, os exemplos são importantes a indicar possibilidades de reversão atual do sentido geral da educação, ciência, tecnologia e inovação no Brasil. Mais detalhes, em: DEMO, 2011; FONSECA, 1986; PORTELA ; SCHUMACHER, 2019; ATTUY, 2006; POCHMANN, 2017. 


\section{CONSIDERAÇÕES FINAIS}

Prestes a completar duzentos anos de sua independência nacional, o Brasil depara-se com questões formuladas há cem anos. $O$ atraso nacional identificado desde as primeiras décadas de 1930 enquanto decorrência da inserção tardia e periférica no sistema capitalista mundial pressuporia uma inflexão na trajetória pregressa do país.

Não obstante as significativas transformações nacionais, o Brasil completou o primeiro quarto do século $20 \mathrm{com}$ questionamento crescente acerca dos rumos mais recentes assumidos em termos do aprofundamento da dependência tecnológica externa e da regressão ao subdesenvolvimento. Sobre isso, aliás, as páginas anteriores procuraram situar, tendo como referência a complexidade expansionista do denominado capitalismo 4.0.

O resgate da trajetória de longo prazo da educação brasileira, ainda que breve, visou oferecer algumas pistas sobre a sua situação no período recente. Da mesma forma, a análise da condição de estagnação do capitalismo brasileiro e de suas consequências para o mundo do trabalho atual apresentaram algumas preocupações em torno dos resultados alcançados pelas respostas educacional, científica e tecnologia mais recentemente adotadas frente ao reposicionamento brasileiro no interior da Divisão Internacional do Trabalho. 


\section{REFERÊNCIAS}

ATTUY, G. Programa fomenta desenvolvimento de inovação dentro da empresa. Inovação Uniemp. 2 no .4, set./out. 2006.

BANCO MUNDIAL. La enseñanza superior. Washington: BM, 1995.

BORGES, M. A educação superior numa perspectiva comercial: a visão da Organização Mundial do Comércio. Revista Brasileira de Política e Administração da Educação, v. 25, n. 1, p. 83-91, 2009.

BORÓN, A. (org.) Nova hegemonia mundial. Buenos Aires, Clacso, 2004.

BUARQUE, C. A Revolução Republicana na Educação Ensino de qualidade para todos. São Paulo: Moderna, 2011.

CARLOTTO, M. Veredas da mudança na ciência brasileira. São Paulo. Ed. 34, 2013.

CHAIA, J. Financiamento escolar no segundo Império. Marília: FFCL, 1965.

COSTA, C. ; GOULART, S. Capitalismo acadêmico e reformas neoliberais no ensino superior brasileiro. Cad. EBAPE.BR, v. 16, ㄲo 3, Rio de Janeiro, Jul./Set. 2018.

DÁVILA, J. Diploma of Whiteness: Race and Social Policy in Brazil. Durham, DUP, 2003.

DEMO, P. Educar pela pesquisa. Campinas: Editora Autores Associados, 2011.

DOWBOR, L. O capitalismo se desloca. São Paulo: Sesc, 2020.

DRAIBE, S. Rumos e metamorfoses. Rio de Janeiro: Paz e Terra, 1985.

FERNANDES, F. Universidade brasileira. São Paulo: Alfa-Omega, 1975.

FERREIRA, E. A consolidação do direito à educação como desafio para um Estado de bem-estar no Brasil. In: CASTRO. J. ; POCHMANN, M. Brasil: Estado social contra a barbárie. São Paulo: FPA, 2020.

FONSECA, C. História do ensino industrial no Brasil. 5 vols. Rio de Janeiro: SENAI/DN/DPEA, 1986.

GADOTTI, M. Qualidade na educação: uma nova abordagem. Florianópolis: COEB, 2013.

GENTILI, P. ; SILVA, T. (orgs.) Neoliberalismo, qualidade total e educação: visões críticas. Petrópolis: Vozes, 1995.

GOMES, M. Globalização do conhecimento. Uberaba: UFTM, 2011.

GUIRALDELLI JÚNIOR, P. História da educação. São Paulo: Cortez, 1990. 
GUSMÃO, J. A qualidade da educação no Brasil: consensos e diversidades. São Paulo; FE/USP, 2010.

HUE, S. Primeiras cartas do Brasil. Rio de Janeiro, Zahar, 2006.

KANG, T. Descentralização e financiamento da educação brasileira. Estudos Econômicos, 41(3): 573-599, 2011.

KRÜCKEN, G, et al. (eds.) Towards a Multiversity? Universities between Global Trends and National Traditions. Bielefeld: Transcript, 2007.

MATTOS, V. Pós-graduação em tempos de precarização do trabalho. São Paulo: Xamã, 2011.

MAUÉS, O. O produtivismo acadêmico e o trabalho docente. Universidade e Sociedade, v. 17, n. 41, p. 21-31, 2008.

MELCHIOR, J. A política de vinculação de recursos públicos e o financiamento da educação no Brasil. São Paulo: FE/USP, 1981.

MEYER, J. ; SCHOFER, E. The University in Global Society: Twentieth Century Expansion, Die Hochschule, 14, 2, 81-98, 2005.

OLIVEIRA, M. et al. (orgs.) A qualidade da escola pública no Brasil. Belo Horizonte: Mazza, 2012.

OLIVEIRA, M. O inovacionismo em questão. Scientiae Studia, São Paulo, v. 9, n. 3, p. 669-75, 2011

OURIQUES, N. ; RAMPINELLI, W. Crítica à razão acadêmica. Florianópolis: Insular, 2017.

PAULANI, L. A Crise e o Futuro do Capitalismo. In: PEREIRA, L. (org.) Depois da Crise: a China no centro do mundo? São Paulo: FGV-EESP, 2012.

PELAEZ, V. ; SZMRECSÁNYI, T. (orgs.) Economia da inovação tecnológica. São Paulo: Hucitec, 2006.

PINTO, A. Consciência e realidade nacional. 2 volumes. Rio de Janeiro: ISEB, 1960.

POCHMANN, M. Estado e capitalismo no Brasil: a inflexão atual no padrão das políticas públicas do ciclo político da Nova República. Educação \& Sociedade, Campinas, vol. 38, n. 139, pp. 309330, abr-jun, 2017.

POCHMANN, M. Educação e trabalho: como desenvolver uma relação virtuosa? Educação \& Sociedade, Campinas, vol. 25, n. 87, pp. 383-399, maio/ago. 2004.

PORTELA, K. SCHUMACHER, A. Produção científica e experiências exitosas na educação brasileira. 6. volumes. Ponta Grossa, Atena, 2019.

PRADO JUNIOR, C. Formação do Brasil Contemporâneo: colônia. 12. ed. São Paulo: Brasiliense, 1972.

RAMOS, A. Introdução à cultura. Rio de Janeiro: Cruzada da Boa Imprensa, 1939. 
RAMOS, M. ; ROITMAN, I. A Urgência da Educação. São Paulo: Moderna, 2011.

RIBEIRO, D. A universidade necessária. Rio de Janeiro, Paz e Terra, 1975.

RIBEIRO, M. História da educação brasileira. Campinas: Autores Associados, 2003.

ROCHA, F. ; GIUBERTI, A. Composição do gasto público e crescimento econômico: uma avaliação macroeconômica da qualidade dos gastos dos Estados brasileiros. Economia Aplicada, vol.11. No. 4. Ribeirão Preto, oct.Idec. 2007.

SALM, C. Considerações sobre as relações entre capitalismo e educação. São Paulo, Anais do II Encontro Nacional de Estudos do Trabalho. 1991.

SANTOS, W. Cidadania e justiça: a política social na ordem brasileira. Rio de Janeiro: Campus, 1979.

SAVIANI, D. O legado educacional do "longo século XX" brasileiro. In: SAVIANI, D. et al. O legado educacional do século XX no Brasil. Campinas: Autores Associados, 2004.

SLAUGHTER, S.; RHOADES, G. Academic capitalism and the new economy: market, State and Higher Education. Baltimore: JHU Press, 2004.

SOUZA, R. Templos de civilização. A implantação da escola primária graduada no Estado de São Paulo. São Paulo: UNESP, 1998.

TAMBARA, E. ; ARRIADA, E. (orgs.) Coletânea de leis sobre o ensino primário e secundário no período imperial brasileiro. Pelotas: Seiva, 2005.

TEIXEIRA, A. Educação no Brasil. 2. ed. São Paulo: Nacional/MEC, 1976.

TEIXEIRA, A. O ensino Superior no Brasil. Rio de Janeiro: Ed. FGV, 1969.

UNCTAD Creación y captura de valor. Informe sobre la economia digital. New York: UNP, 2019

UNESCO Global Education Monitoring Report. Paris: UNESCO, 2020.

VIDAL, D. (org.) Grupos escolares. Cultura escolar primária e escolarização da infância no Brasil. Campinas: Mercado das Letras, 2006. 